\title{
Designing $\mathrm{CuO}_{x}$ Nanoparticle-Decorated $\mathrm{CeO}_{2}$ Nanocubes for Catalytic Soot Oxidation: Role of Nano-interface in the Catalytic Performance of Hetero-structured Nanomaterials
}

Putla Sudarsanam, ${ }^{\dagger}$ Brendan Hillary, ${ }^{\dagger}$ Baithy Mallesham, ${ }^{\star}$ Bolla Govinda Rao, ${ }^{*}$ Mohamad Hassan Amin, ${ }^{\dagger}$ Ayman Nafady, ${ }^{\perp}$ Ali M. Alsalme, ${ }^{\perp}$ B. Mahipal Reddy, ${ }^{\ddagger}$ and Suresh K. Bhargava $^{* \dagger}$

$\dagger$ Centre for Advanced Materials and Industrial Chemistry (CAMIC), School of Applied Sciences, RMIT University, Melbourne VIC 3001, Australia

* Inorganic and Physical Chemistry Division, CSIR-Indian Institute of Chemical Technology, Uppal Road, Hyderabad 500 007, India

${ }^{\perp}$ Chemistry Department, College of Science, King Saud University, Riyadh, Saudi Arabia

\| Chemistry Department, Faculty of Science, Sohag University, Sohag, Egypt 

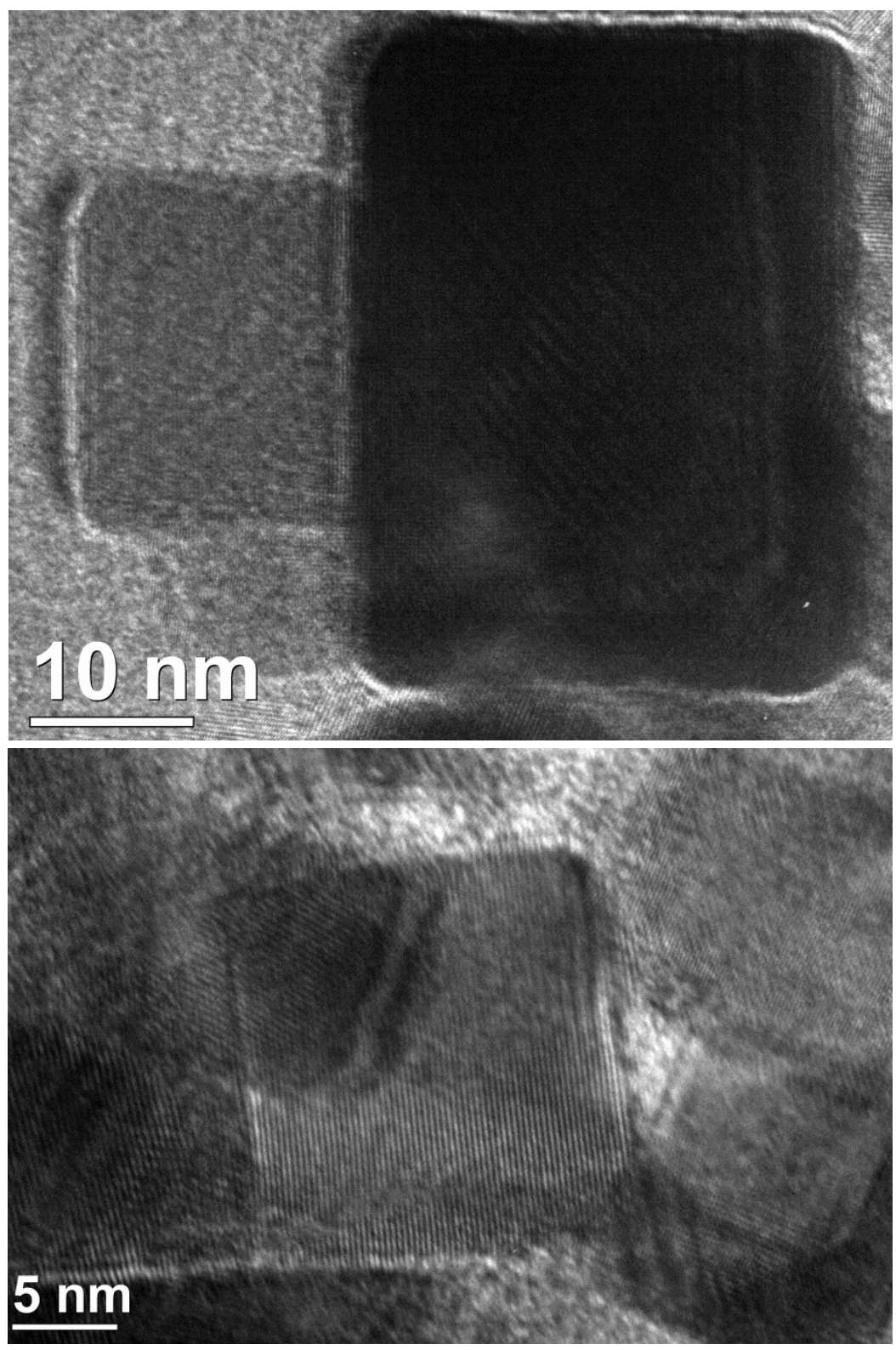

Figure S1. TEM images of $\mathrm{CeO}_{2}$ nanocubes. 


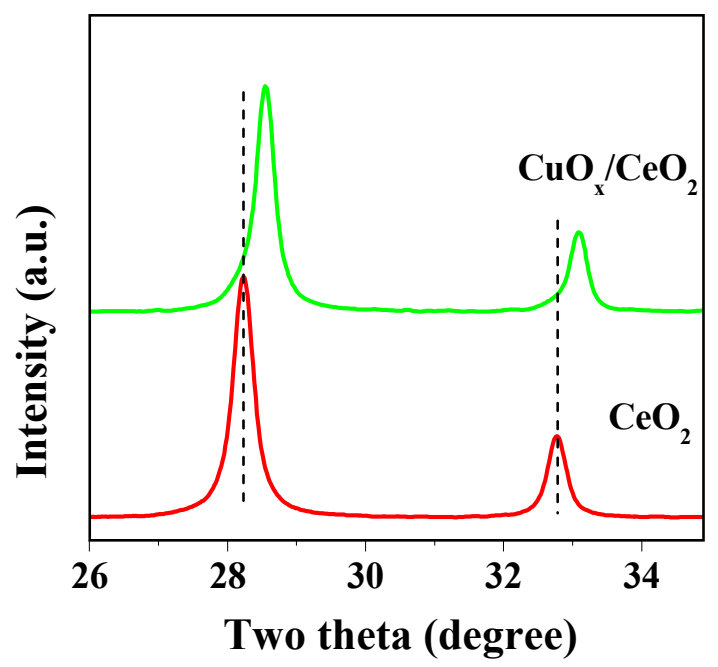

Figure S2. Magnified powder $\mathrm{XRD}$ patterns of $\mathrm{CeO}_{2}$ nanocubes and $\mathrm{CuO}_{\mathrm{x}}$-decorated $\mathrm{CeO}_{2}$ nanocubes. 


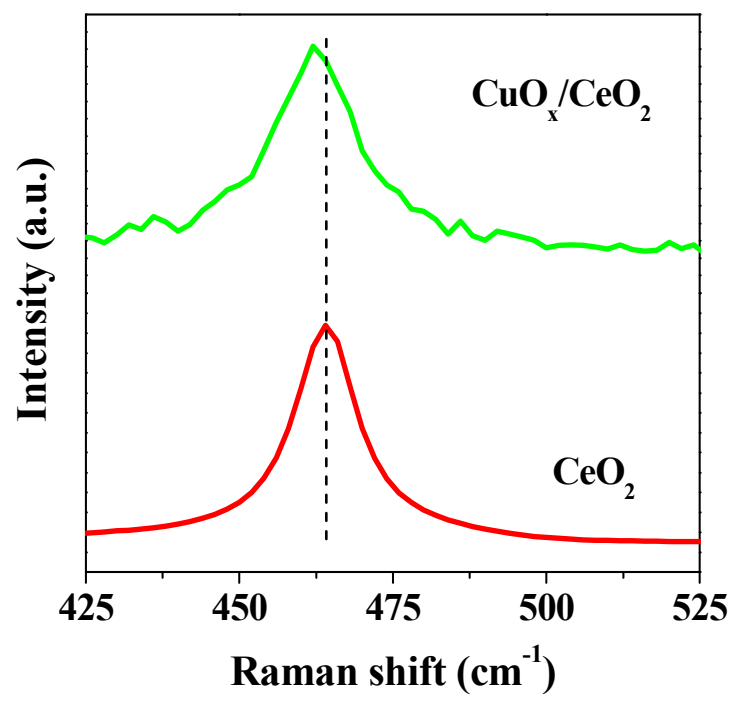

Figure S3. Magnified Raman spectra of $\mathrm{CeO}_{2}$ nanocubes and $\mathrm{CuO}_{\mathrm{x}}$-decorated $\mathrm{CeO}_{2}$ nanocubes. 


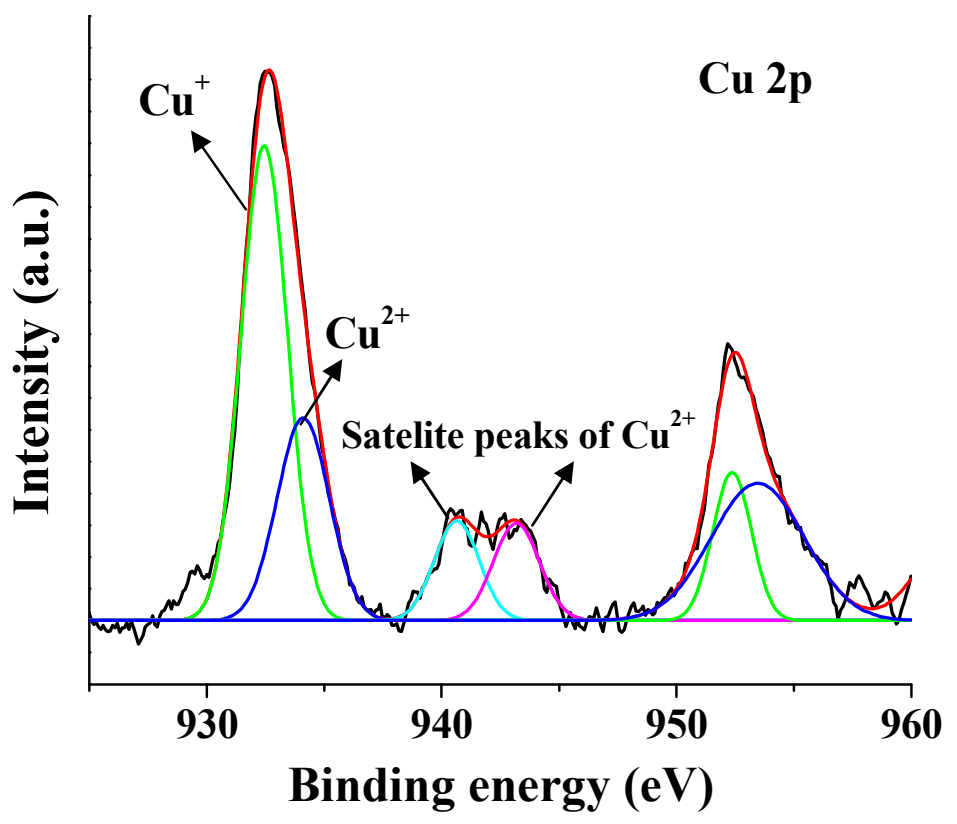

Figure S4. $\mathrm{Cu} 2 \mathrm{p}$ XPS spectrum of $\mathrm{CuO}_{\mathrm{x}}$-decorated $\mathrm{CeO}_{2}$ nanocubes. 


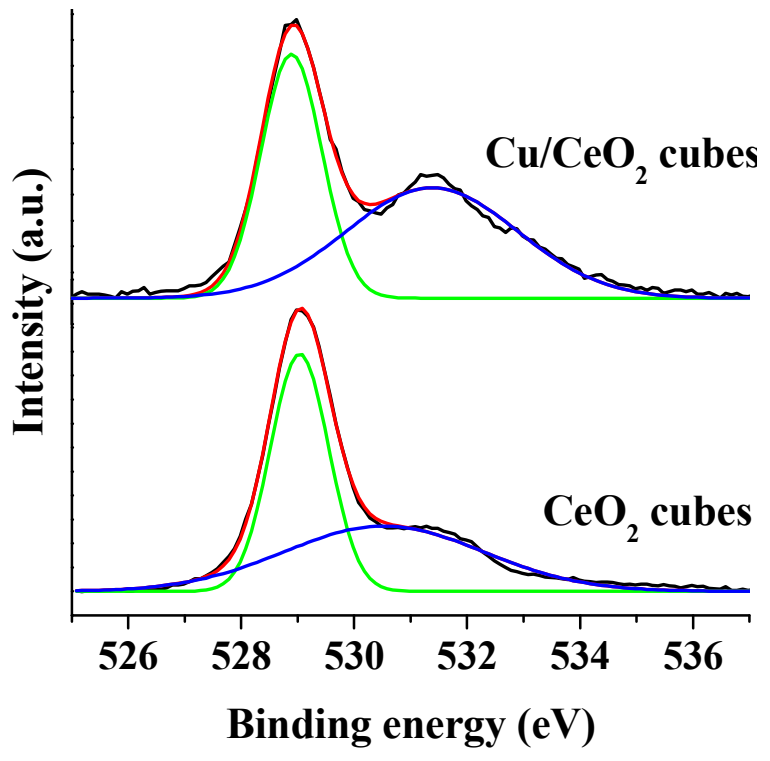

Figure S5. O 1s XPS spectra of $\mathrm{CeO}_{2}$ nanocubes and $\mathrm{CuO}_{\mathrm{x}}$-decorated $\mathrm{CeO}_{2}$ nanocubes. 